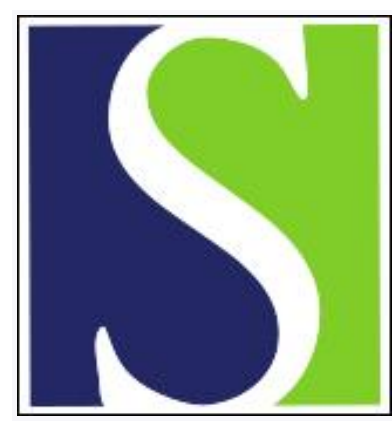

Scand J Work Environ Health 1992;18(3):201-204

https://doi.org/10.5271/sjweh.1587

Issue date: 01 Jun 1992

\title{
Cancer mortality among licensed herbicide applicators.
}

by Swaen GM, van Vliet C, Slangen JJ, Sturmans F

Affiliation: Department of Occupational Medicine, Environmental Health and Toxicology, University of Limburg, The Netherlands.

This article in PubMed: www.ncbi.nlm.nih.gov/pubmed/1615295 


\title{
Cancer mortality among licensed herbicide applicators
}

\author{
by Gerard MH Swaen, PhD, ${ }^{1}$ Cornelis van Vliet, MD ${ }^{1,2}$ Joseph JM Slangen, ${ }^{1}$ \\ Ferdinand Sturmans, $\mathrm{MD}^{3}$
}

\begin{abstract}
SWAEN GMH, VAN VLIET C, SLANGEN JJM, STURMANS F. Cancer mortality among licensed herbicide applicators. Scand J Work Environ Health 1992;18:201-4. This retrospective cohort study investigated the cancer mortality of 1341 herbicide applicators licensed before 1 January 1980. The cohort was followed for mortality until 1 January 1988 by means of the Dutch system of population registers. For the subjects who died before 1 January 1988 the cause of death was obtained from the Central Bureau of Statistics. The cause of death was obtained for $98.4 \%$ of the deceased subjects. The total mortality was lower than expected according to mortality rates of the total male Dutch population. The total number of deaths from cancer was however slightly higher than expected [standardized mortality ratio (SMR) 114]. Mortality from several subtypes of cancer was also higher than expected, that for multiple myeloma being statistically significantly higher than unity (SMR 815, 95\% confidence interval 164-2382). Occupational exposure to herbicides appears to increase the risk for multiple myeloma and possibly other malignant neoplasms
\end{abstract}

Key terms: epidemiology, herbicides, occupational exposure.

The first reports on the existence of possible long-term health effects related to herbicide exposure originated from Sweden $(1-3)$. In these studies elevated risks for soft-tissue sarcoma and lymphoma were reported for persons exposed to phenoxy herbicides and chlorophenols. The results triggered several other epidemiologic studies attempting to replicate these findings. In these efforts both the cohort and the case-referent design were used. All three exposure groups (formulators, professional applicators and farmers) were studied. Among the neoplasms found to be related to herbicide exposure were lymphatic and hematopoietic neoplasms, multiple myeloma, lung cancer, leukemia, prostate cancer, and gastric cancer. The results of the epidemiologic studies have been reviewed by Blair \& Zahm (4).

One of the methodological difficulties in epidemiologic studies attempting to evaluate the long-term health risks of herbicide exposure is to identify a cohort of persons who have been exposed to herbicides in the past. One surrogate indicator of past exposure is a license to carry out the spraying of these agents. Several epidemiologic studies have been specifically designed to investigate the cancer risk of licensed pesticide applicators. In one study the mortality experience

\footnotetext{
1 Department of Occupational Medicine, Environmental Health and Toxicology. University of Limburg, The Netherlands.

2 Current address: Dutch Labour Inspectorate, The Hague, The Netherlands.

${ }^{3}$ Department of Epidemiology, University of Limburg, Limburg, The Netherlands.
}

Reprint requests to: Dr GMH Swaen, Department of Occupational Medicine, Environmental Health and Toxicology. PO Box 616, 6200 MD Maastricht, The Netherlands. of 3827 white men licensed to apply pesticides in Florida was evaluated (5). The overall mortality of this cohort was close to the expected number. However, an elevated mortality rate was observed for leukemia and lung cancer. In another study the cancer incidence of 25945 Italian farmers licensed to work with pesticides was investigated by means of a linkage system with hospital data (6). In this group the incidence of malignant skin cancers, lymphomas, tumors of the central nervous system, and neoplasms of hematopoietic tissue appeared to be higher than expected.

The specific aim of our study was to evaluate the cancer risks of a group of licensed herbicide applicators. No information on the occurrence of cancer in this cohort was known to the investigators prior to the study.

\section{Subjects and methods}

In The Netherlands there is a central agency that keeps a record of persons who have been licensed as herbicide applicators. The register of this agency was used to identify a cohort with probable past exposure to herbicides. Only those herbicide applicators were included who were certified before 1980 . This cohort restriction was made to ensure that a latency period of at least nine years had elapsed for all of the subjects. Altogether 1341 persons had been certified as a licensed herbicide applicator before 1980 . These persons were all followed for mortality until 1 January 1988.

Each of the 650 municipalities in The Netherlands keeps a detailed population register of its residents. If a person moves from one municipality to another he or she is registered in both municipalities. Thus it was possible for us to follow the subjects by means of the 
municipal population registers, provided that the last known address was available. Table 1 presents the results of the follow-up.

At death a death certificate must be filed on which the underlying cause of death has been recorded by a physician. The Central Bureau of Statistics receives a copy of all death certificates, codes them according to the International Classification of Diseases, and uses them to generate disease-specific annual vital statistics. Although the Bureau does not provide individual causes of death to a third party, frequency distributions of the causes of death for specific groups or subgroups can be obtained once it is ensured that the privacy of the individuals is well protected. After the vital status as of 1 January 1988 was determined for the total study population, the Bureau was requested to give us the opportunity to analyze the causes of death for the

Table 1. Results of the follow-up of the cohort until 1 January 1988.

\begin{tabular}{lrr}
\hline & \multicolumn{2}{c}{ Workers } \\
\cline { 2 - 3 } & $\mathrm{N}$ & $\%$ \\
\cline { 2 - 3 } Total cohort & 1341 & 100 \\
Died before 1 January 1988 & 63 & 4.7 \\
Emigrated before 1 January 1988 & 5 & 0.4 \\
Lost to follow-up & 1 & 0.1 \\
Alive on 1 January 1988 & 1272 & 94.8 \\
\hline
\end{tabular}

Table 2. Breakdown of the total municipal herbicide use in 1980 by specific agent.

\begin{tabular}{lrc}
\hline Agent & $\begin{array}{c}\text { Weight } \\
(\mathbf{k g})^{\mathrm{a}}\end{array}$ & $\begin{array}{c}\text { Percentage } \\
\text { of total } \\
\text { use }\end{array}$ \\
\hline Amitrole & 3382 & 3.5 \\
Ammonium sulfate & 2312 & 2.4 \\
Ammonium cyanate & 175 & 0.2 \\
Atrazine & 2174 & 2.3 \\
Bromacil & 39 & 0.1 \\
2,4-Dichlorophenoxyacetic & 3613 & 3.8 \\
acid & 1607 & 1.7 \\
Dalapon & 1364 & 1.4 \\
Diquat & 6176 & 6.4 \\
Diuron & 2208 & 2.3 \\
Glyphosate & 3144 & 2.3 \\
2-Methyl-4-chlorophenoxy- & & \\
acetic acid & 2160 & 2.3 \\
2-(2-Methyl-4-chlorophenoxy)- & 1653 & 1.7 \\
propionic acid (mecoprop) & 5841 & 6.1 \\
Sodium chlorate & 26034 & 26.9 \\
Paraquat & 31464 & 32.5 \\
Simazine & 96755 & 100.0 \\
Granulates & & \\
\hline Total & & \\
\hline
\end{tabular}

a Of active agent.

b Granulates based on chlorothiamide, dalapon, dichlobenil, diuron, simazine, or their combinations. deceased workers. This request was granted, and the Bureau was able to link $98.4 \%$ (62 out of 63 ) of the deaths to a specific cause.

The statistical analysis consisted of a person-time analysis. The person-years of observation were calculated specifically for age groups and calendar periods. Persons who were lost to follow-up were treated as being in the study until the date on which they were lost to follow-up. This procedure was also followed for the workers who had emigrated. Altogether 17374 person-years of follow-up were generated in the study. These age- and period-specific person-years were multiplied by the cause-specific mortality rates of the total Dutch male population for the expected number of deaths by cause.

The standardized mortality ratios (SMR) were calculated by dividing the observed number of deaths by the expected number and multiplying by 100 , and the $95 \%$ confidence intervals $(95 \% \mathrm{CI})$ were calculated according to the method proposed by Breslow \& Day (7).

The exposed group was also divided into several subgroups on the basis of information about the specific jobs held by the subjects at the time of licensing, as stated on the certificate. The subclassification was designed to exclude all subjects that were likely to have been engaged in supervisory work instead of actually spraying herbicides. In this fashion the cohort was reduced to 921 workers, but with more definite exposure to herbicides.

No data were available on the qualitative and quantitative exposure of the workers. However, the Central Bureau of Statistics had carried out an inventory of pesticides applied by governmental agencies in 1980 (8). This survey consisted of a questionnaire sent to every municipality. The response rate was $89.9 \%$. Of the total weight of $112308 \mathrm{~kg}$ of pesticides applied by the municipalities, $96755 \mathrm{~kg}(86.2 \%)$ were herbicides. Table 2 presents the distribution of specific agents used by the municipalities in 1980 . Although these data do not prove that the workers were exposed to these agents, they form an indication of the type of agents to which they might have been exposed.

\section{Results}

The total mortality of the cohort of licensed herbicide applicators was lower than expected (table 3). Sixtythree deaths were observed versus an expected number of 83.3 (SMR 76, 95\% CI 58-97). A lower mortality than expected is often observed in retrospective cohort studies and is often referred to as the healthy worker effect. Despite the healthy worker effect, however, the mortality from cancer was higher than expected. Thirty-one workers died of cancer as compared with an expected number of 27.2 (SMR $114,95 \%$ CI $77-162$ ). The mortality from several subtypes of cancer was particularly elevated.

Mortality from skin cancer, pancreatic cancer, brain tumors, and multiple myeloma was higher than ex- 
pected. Despite the limited sample size of the study, the SMR for multiple myeloma reached statistical significance (SMR 815, 95\% CI 164-2382).

In the group of 921 workers with more probable exposure to herbicides we found one case of skin cancer ( 0.27 expected), two brain tumors $(0.62$ expected), and one Hodgkin's lymphoma ( 0.2 expected). All of the observed deaths from multiple myeloma occurred in this group, the SMR becoming 1299 (95\% CI 2613795). The three deaths from pancreatic cancer also occurred in this group when only 0.867 were expected (SMR 346, 95\% CI 70-1011). In addition the SMR for total cancer mortality increased to 128 .

\section{Discussion}

The aim of this study was to investigate the cancer risks of a cohort of licensed herbicide applicators in The Netherlands. Although the exposed group was limited, several notable observations were made. Particularly in light of the clear healthy worker effect, the higher total cancer mortality (SMR 114) was an important finding. The elevated SMR values for several cancer types are a reason for concern. There were two deaths from skin cancer, which can be considered an indication of a cancer risk related to exposure to herbicides. A possible relation between skin cancer and exposure to herbicides has been suggested by others (9). However, it is also possible that the increase in cancer mortality was associated with occupational exposure to sunlight, as suggested by Corrao et al (6).

There were three deaths from brain tumors compared with an expected number of 0.9 (SMR 318, 95\% CI 64-930). Although this result is not statistically significant, it is in agreement with earlier findings (10). Several other studies of workers exposed to herbicides did not however produce any evidence of such a relationship.

The mortality from multiple myeloma was statistically significantly higher than expected (SMR 815, 95\% CI 164- 2382). The SMR increased to 1299 for the subgroup with a very high probability of having carried out actual spraying work. In several other epidemiologic studies excesses of mortality from multiple myeloma have been reported. Coggon et al (10), for instance, observed five deaths from multiple myeloma compared with three expected deaths in a cohort of workers exposed to 2,4-dichlorophenoxyacetic acid and other phenoxy acid herbicides. In a case-referent study of multiple myeloma Pearce et al (11) noted an odds ratio of $\mathbf{1 . 3}$ for farmers who had ever sprayed agricultural chemicals. This result did not, however, reach statistical significance. In an ongoing prospective study of herbicide applicators in Finland, one case of multiple myeloma was found, compared with the $0.2 \mathrm{ex}-$ pected (12).

Several limitations of this study should be noted. The certification as herbicide applicator was taken as a surrogate of exposure, although certification does not
Table 3. Cause-specific mortalitya of the cohort. (SMR = standardized mortality ratio, $95 \% \mathrm{Cl}=95 \%$ confidence interval)

\begin{tabular}{lrrc}
\hline Cause of death & $\begin{array}{c}\text { Observed } \\
\text { deaths } \\
\text { (N) }\end{array}$ & SMR & $95 \% \mathrm{Cl}$ \\
\hline Infectious disease & - & 0 & $\cdot$ \\
Neoplasms & 31 & 114 & $77-168$ \\
$\quad$ Stomach + small intestine & 1 & 48 & $1-266$ \\
$\quad$ Large intestine & 4 & 255 & $69-654$ \\
Pancreas & 3 & 218 & $44-637$ \\
Trachea + lung & 12 & 107 & $55-186$ \\
Skin & 2 & 483 & $54-1744$ \\
Prostate & 1 & 131 & $2-731$ \\
Hodgkin & 3 & 318 & $64-930$ \\
Multiple myeloma & 1 & 334 & $4-1861$ \\
Kidney & 3 & 815 & $164-2382$ \\
Circulatory system & 1 & 114 & $2-632$ \\
Respiratory system & 20 & 60 & $37-94$ \\
Digestive system & - & 0 &. \\
Others & - & 0 &. \\
External causes & 1 & 12 & $0-66$ \\
Unknown cause of death & 10 & 122 & $58-224$ \\
\hline Total & 1 & $\cdots$ & $\ldots$ \\
\hline
\end{tabular}

a Only neoplasms that have been observed in the cohort are given. Therefore the expected numbers of the tabulated subtypes do not add up to the expected number of neoplasms.

b This category includes causes such as accidents and violence.

necessarily mean that the person had definitely experienced exposure to herbicides. In this study misclassification of exposure would surely have led to an underestimation of the true relative risks, however, since it would have diluted the elevated SMR values. Unfortunately no data exist on what particular herbicide the cancer cases had been exposed to in the past. Thus it is not possible to link the observed cancer risk to a particular type of herbicide.

Several strong points of this study should also be noted. The underlying causes of death were all recorded and coded by trained nosologists at the time of death, and none of the nosologists were aware of this study nor of the exposure status of the deceased. Hence no bias due this type of misclassification or miscoding can have occurred. It should also be kept in mind that this study was not triggered by an unusual case report in the study population. In fact no occurrence of cancer or any other disease in the study population was known prior to the start of the study, the cohort selection, or the follow-up.

Exposure to herbicides can occur both during the handling of herbicides and the actual spraying work. It has been stated that skin contact is responsible for the greater proportion of the internal dose of herbicides (13). Occupational measures should be taken to minimize exposure to herbicides, both during handling and during the actual spraying work.

This study provides additional evidence for a relationship between occupational exposure to herbicides and cancer. In view of this relationship it should be noted that several of the neoplasms thought to be associated with exposure to herbicides originated in the lymphoreticular system, such as leukemia, non-Hodg- 
kin's lymphoma, and multiple myeloma. This observation indicates that the increased risks for these three types of neoplasms may have a common mechanism.

\section{Acknowledgments}

We thank the Central Bureau of Statistics for its cooperation with the project and for providing the causes of death for the workers in the study. We also thank the Dutch Certification Agency for their participation in the project.

\section{References}

1. Hardell L, Sandstrom A. Case-control study: soft-tissue sarcomas and exposure to phenoxyacetic acids or chlorophenols. Br J Cancer 1979;39:711-7.

2. Eriksson ML, Hardell P, Berg NO, Moller T, Axelson $O$. Soft-tissue sarcomas and exposure to chemical substances: a case-referent study. Br J Ind Med 1981;38: 27-33.

3. Hardell L, Eriksson M, Lenner P, Lundgren E. Malignant lymphoma and exposure to chemicals especially organic solvents, chlorophenols and phenoxyacids: a casecontrols study. Br J Cancer 1981;43:169-76.

4. Blair A, Zahm SH. Herbicides and cancer: a review and discussion of methodologic issues. In: Band P, ed. Occupational cancer epidemiology. Berlin: Springer Verlag, 1990.

5. Blair A, Grauman DJ, Lubin JH, Fraumeni JF. Lung cancer and other causes of death among licensed pesti- cide applicators. J Natl Cancer Inst 1983;1:31-7.

6. Corrao G, Calleri M, Carle F, Russo R, Bosia S, Piccioni $P$. Cancer risk in a cohort of licensed pesticide users. Scand J Work Environ Health 1989;15:203-9.

7. Breslow NE, Day NE. Statistical methods in cancer research; vol II (The design and analysis of cohort studies). Lyon: International Agency for Research on Cancer, 1987.

8. Centraal Bureau voor de Statistiek. Gebruik van chemische bestrijdingsmiddelen door overheidsinstellingen 1980. 's-Gravenhage: Staatsuitgeverij, 1984.

9. Wang JD, Li WE, Hu KH. Occupational risk and the development of premalignant skin lesions among paraquat manufactures. Br J Ind Med 1987;44:196-200.

10. Coggon D, Pannet B, Winter PO, Acheson ED, Bonsall J. Mortality of workers exposed to 2-methyl-4 chlorophenoxyacetic acid. Scand J Work Environ Health 1986;12:448-54.

11. Pearce NE, Smith AH, Howard JK. A case-control study of multiple myeloma and farming. Br J Cancer 1986; 54:493-500.

12. Riihimaki V, Sisko A, Hernberg S. Mortality of 2,4dichlorophenoxyacetic acid and 2,4,5-trichlorophenoxyacetic acid herbicide applicators in Finland: first report of an ongoing prospective cohort study. Scand J Work Environ Health 1982;8:37-42.

13. World Health Organization (WHO). Recommended health based exposure limits in occupational exposure to pesticides: report of a WHO study group. Geneva: WHO, 1982.

Received for publication: 24 May 1991 